\title{
Introduction to the Special Section on DSM-5: Classifying Sex
}

\author{
Véronique Mottier $^{1,2} \cdot$ Robbie Duschinsky ${ }^{3}$
}

Published online: 15 May 2015

(c) Springer Science+Business Media New York 2015

The publication of the 5th revision of the Diagnostic and Statistical Manual of MentalDisordersin May 2013 occurred within a radically different social and political context from that of the first DSM in 1952. In hindsight, the 1950s were the last decade of an era when psychiatric practices were relatively little contested. In contrast, the DSM-5 is very much a product of the twenty-first century: while the DSM still constitutes an authoritative source of psychiatric classifications for medical practitioners in the US and many other countries, patients and advocacy groups nowadays talk back and voice criticism of the labels that are being applied to them. Indeed, such views were solicited as part of the process that led to the DSM-5, something which would have been unthinkable in the 1950s.

The articles collected in this special section were initially presented at the interdisciplinary conference "Classifying Sex: Debating the DSM- $5^{1}$ organized by sociologists Robbie Duschinsky and Véronique Mottier, which took place shortly after the publication of DSM-5, on 4 and 5 July 2013 at the Centre for Research in the Arts, Social Sciences and Humanities (CRASSH) of the University of Cambridge. ${ }^{2}$ Speakers at the conference mostly came from the social sciences, but also included two members of the DSM-5 Sexual and Gender Identity Disorders Work Group: Kenneth J.Zucker and Cynthia Graham. The conference papers presented by the latter (and several others) appear in a special issue of Psychology \& Sexuality titled "The DSM-5 as Political

Véronique Mottier

vm10004@cam.ac.uk

1 Jesus College, University of Cambridge, Cambridge CB5 8BL, UK

2 Laboratoire de Sociologie, University of Lausanne, 1015 Lausanne, Switzerland

3 Department of Social Work \& Communities, Northumbria University, Newcastle, UK
Battleground: Gender Identities, Sexual Norms, and Female Desire,"guest-edited by Robbie Duschinsky and Véronique Mottier. Other papers, specifically on the theme of sexual classifications, form the contents of this special section of the Archives.

Sexual classifications have been a source of particularly vehement debate within the history of the DSM. They are not only tools of psychiatric practice, but also deployed within social and political arenas, as well as everyday life. Against this backdrop, the seven contributors to this special section - prominent feminist, queer, and trans scholars, social and political scientists, and historians of sexuality ${ }^{3}$ - focus on the wider social and political implications of the sexual classifications produced by the DSM5 , and of sexual classification systems more generally. The articles in this special section thus move away from psychiatric or sexological discussion of sexual categories. Instead, they all highlight in different ways the personal, political, and social consequences of sexual classifications and classification systems.

The special section opens with an article by one of the pioneers of critical histories of sexuality, the British sociologist Jeffrey Weeks, entitled "Beyond the Categories." Weeks retraces the birth of sexual classifications within late nineteenth and early twentieth century psychiatry and sexology, thereby placing contemporary debates on successive editions of the DSM within a wider timeframe. He shows how early sexologists introduced the psychiatrization of sexual practices and preferences, by

\footnotetext{
${ }_{1}$ Online version accessible at: http://www.tandfonline.com/doi/abs/10. 1080/19419899.2015.1024468\#.VR5VM-Evslo).

2 The conference was supported by CRASSH, the Wellcome Trust, the Sexual Divisions Study Group of the British Sociological Association, the Institut Français, Northumbria University, the Laboratoire de Sociologie Université de Lausanne, and The Gender Identity Research and Education Society (GIRES).

3 Artworks by Bárbara G.F. Muriel and Tilla Crowne which critically explored the theme of sexual classifications and their effects were also presented during the conference.
} 
classifying particular practices (especially those that could not lead to reproduction) as "perversions" explained by mental deviations. As for current psychiatrists using DSM classifications, their aim, Weeks reminds us, was to provide a more humane treatment of gender and sexual variations compared with the moral disapproval of earlier, Christian notions of sexual "sins," which interpreted gender and sexual "deviations" in terms of moral failures. More recently, he points out, debates over sexual classifications have moved from the question of whether some practices should be diagnosed in terms of sexual "pathologies" to controversies over whether they could be defined as "harmful." Contemporary critical debates within queer and feminist theory and activism often emphasize the negative consequences of sexual classifications altogether, and highlight the ways in which these limit the scope of our gender and sexual possibilities. Yet, Weeks points out, there is also an emotional cost to trying to live outside of any classification at all.

Commenting on a thought-provoking recent documentary portrait of a Cypriot drag performance artist called Shushu, who refuses toidentify himself with conventional categories of gender or sexuality such as man, woman, transsexual, transvestite, transgender, gay or heterosexual, Weeks observes that this refusal triggers important existential and relational difficulties in Shushu's everyday life. It is crucial to recognize, he suggests, that psychiatric and sexological classifications are not "natural" but historical, and to worry about their personal as well as political consequences. But, in our current world, it is no longer possible to live without labels, Weeks argues.

When we ignore the historical origins of sexual classifications, the next article argues, the political "work" which sexual classifications perform remains obscured. In "The Imperialism of Historical Arrogance: Where is the Past in the DSM's Idea of Sexuality?", British classical scholar and historian of sexuality Simon Goldhill turns to the example of classifications of prostitution, as a lens on broader questions to do with how sexuality comes to be divided between acceptable or aberrant within classificatory discourses. Goldhill points out that, in the nineteenth century, a key moment in the rise of psychology as a recognized medical discipline, expert discourses from psychologists and psychiatrists (including Freud) portrayed prostitutes as suffering from psychological abnormalities which predisposed them towards immoral sexual practices. This medicalization and psychiatrization of prostitution in the Victorian era was, Goldhill suggests, closely intertwined with its legal and social regulation at the time, which stigmatized female prostitutes (rather than their male clients) and thus had deeply gendered effects. Current debates on the regulation of prostitution sometimes echo these earlier historic meanings, and yet seem oblivious to their historic roots.

A specialist in Classical Antiquity, Goldhill argues that recent debates over the category of hebephilia (which had been proposed for inclusion in DSM-5, but was rejected) seemed tellingly unaware of history. In the classical world of ancient Greece, sexual relations between adult men and adolescents carried very different cultural meanings from today. There is a certain irony, he points out, in the fondness of contemporary American psychiatrists for the use of ancient Greek-sounding terms to diagnose sexual practices which ancient Greek culture saw as perfectly respectable (such as the sexual desire for, and courtship of, male adolescents by adult men) as a sign of mental disorder. More generally, Goldhill argues that revision processes of the DSM have been insufficiently sensitive to the historical and cultural variation of sexual meanings, thereby undermining their own commitment to authoritative, transhistorical scientific norms.

While Goldhill thus highlights important flaws in the debates over the category of hebephilia, these did not cause the rejection of this category as a candidate for DSM-inclusion. An analysis of these causes is undertaken by the Swiss-American historian and philosopher of science Patrick Singy in his article titled "Hebephilia: A Post-Mortem Dissection."His text starts by examining the empirical evidence for the actual existence of a sexual preference for adolescents (which the term "hebephilia"was meant to capture), and concludes that the data are, in themselves, persuasive and relatively uncontroversial. Against this backdrop, Singy asks how we can explain the non-inclusion of the condition, promoted by Ray Blanchard, in the course of the revision process of the DSM. Singy argues that three arguments might be considered to explain this failure to include hebephilia in the new DSM-5: firstly, he thinks that its author focused too much on the question of whether hebephilia exists, and not enough on the question of whether it can be considered a disease. Secondly, the fact that a sexual preference for adolescents seems to be quite common led other experts to object that it should therefore not be considered a mental illness. Singy contends, however, that both of these reasons were not decisive factors for the rejection of the label. Indeed, Singy argues that hebephilia was not accepted because Blanchard neglected to develop his claims in response to a third issue: that of the social consequences of the possible inclusion of this category, especially its consequences for forensic and legal practice. Forensic and legal considerations were explicitly taken into account in the DSM revision processes, and Singy believes that they are a particularly sensitive point in the case of hebephilia against the wider backdrop of the rise in socalled SVP laws in the US, which allow for the incarceration of individuals convicted of sex crimes on the grounds of future potential dangerousness to society. Singy argues that the APA was wary of seeing the DSM used to further expand the scope of already contentious SVP laws, and that Blanchard failed to recognize the importance of this potential obstacle to the absorption of this category in the DSM-5-ironically, given his own expressed discomfort with such laws.

The article "Becoming Gay? Immigration Policies and the Truth of Sexual Identity" by French sociologists and gender scholars Éric Fassin and Manuela Salcedo moves away from internalDSM debates to examine more widely the ways in which sexual classifications operate within the political arena today. 
Fassin is also a prominent critical voice in current public debates over the politics of gender, sexuality, immigration and race in France. Focusing specifically on the category of homosexuality, Fassin and Salcedo echo Weeks and Goldhill in highlighting its relatively recent historic origins in late nineteenth century European psychiatric and medical discourses. However, they observe that the term homosexuality is not necessarily used in the same way by individuals living in non-Western contexts today. Fassin and Salcedo examine how Western and non-Western sexual categories confront each other in the context of current immigration policies in Europe. Since 2004, a European Union directive has allowed for the persecution of homosexuality to be evoked as a legitimate ground for the granting of asylum. This, Fassin and Salcedo point out, has effectively created the new category of "sexual refugees," requiring border authorities to determine whether a potential applicant is a "true homosexual" or "faking it."

Fassin and Salcedo explore the complex ways in which nonWestern sexual refugees who are caught up in these immigration procedures self-identify with or alternatively reject the label "homosexual," through ethnographic fieldwork carried out in Paris. In their study, they observed and interviewed same-sex couples where one partner is French, and the other non-French, from a culture where embracing an openly gay identity would put them at risk of stigmatization or actual violence. Their data show that individuals negotiate sexual categories in complex and, at times, contradictory ways. Fassin and Salcedo (like Weeks) thus remind us that individuals do not necessarily use the categories that psychiatrists or policy-makers or classificatory systems like the DSM-5 apply to them when they make sense of their everyday lives. And yet, political practices such as immigration procedures sometimes draw them into an engagement with these terms as the basis for identity claims they may need to make to psychiatric or state organizations, and hence negotiate also in their relationships.

The DSM is not the only influential system of classification of mental disorders in operation in today's global world, however. The article by French (self-described) "undisciplined" social psychologist Alain Giami entitled "Between DSM and ICD: Paraphilias and the Transformation of Sexual Norms" proposes a comparison between the DSM and its most influential international "competitor," the International Classification of Diseases (ICD) produced by the World Health Organization, which is in the process of a revision slated for publication in 2017.

The article places the proposed revisions in their historical context, and analyzes the differences between the organizational frameworks which produced the DSM and ICD classifications, before focusing on the guiding principles of the respective revision processes. Giami argues that the sexual classifications which were produced (and revised) by the DSM and the ICD express important normative models of gender as well as of sexuality. While those produced by the DSM have attracted considerable scrutiny, Giami points out that the ICD has, in comparison, been little discussed to date. Drawing on his observations of the ICD revision processes (in which the author was personally involved), Giami notes that these involved important changes in terminology with the dropping of terms such as "sexual perversion" in favor of the new terminology of "paraphilias" or "sexual preference disorders." These changes, he argues, signal an important historic shift away from the pathologization of non-reproductive sexual practices which so characterized late nineteenth and twentieth century sexual classifications, highlighted by Weeks and Goldhill. Instead, Giami argues, current models of "normal" and "abnormal" sexuality tend to draw the dividing line around the notion of consent between sexual partners. Consequently, the main problem for the category of paraphilia, Giami suggests, becomes how to divide between sexual practices which are seen as psychologically "abnormal" and those which fall within the realm of the criminal justice system - a difficulty which clearly also played a role in the debates over hebephilia analyzed by Singy and Goldhill.

Like Giami, Lisa Downing, the British cultural theorist and historian of sexology, critically analyzes the normative models of gender and sexuality which underlie the treatment of paraphilias in her article "Heteronormativity and Repronormativity in Sexological 'Perversion Theory' and the DSM-5's 'Paraphilic Disorder' Diagnoses." Downing points out that the DSM-5 has shifted in focus from paraphilias to paraphilic disorders, where only the latter category is defined as a mental disorder, and notes that this change has been widely welcomed as an improvement upon earlier versions of the DSM. Her position is different from that of Giami, however, in that she does not agree with his observation that we are witnessing a significant shift away from the classification of non-reproductive sexual practices as pathological in previous editions of the DSM, to a current pathologization of non-consensual sex.

Writing from a queer-theory perspective, Downing's article starts with a critical analysis of historical discourses on sexuality to show that these conventionally defined coital and reproduction-oriented practices as "normal" and "natural," and to highlight some of the continuities with contemporary psychiatric discourses. Pointing at the current classification of extreme BDSM practices, such as recreational asphyxiophilia (where individuals derive erotic pleasure from a restriction on breathing) as paraphilic disorders, she asks rhetorically why no-one gets labelled as mentally ill for engaging in non-sexual but also potentially life-threatening activities, such as judo or bungee-jumping. In Downing's view, the historic roots of psychiatric discourse in "repronormativity" (i.e., the notion that "normal" sexual practices are those that may lead to reproduction) continue to cast long shadows over current DSM classifications.

Cynthia Kraus, the Swiss philosopher of science and feminist scholar, turns away from the debates over paraphilias to focus instead on another category which has proved contentious in the revision process, that of "intersex"(defined in terms of physical abnormalities of the sex organs). In her article "Classifying 
Intersex in DSM-5: Critical Reflections on Gender Dysphoria," Kraus proposes a detailed analysis of the DSM texts that relate to intersex, pointing out that this category was defined in DSM-IV as a criterion which served to exclude patients from the diagnosis of Gender Identity Disorder. The DSM-5, in contrast, places intersex in the realm of Disorders of Sex Development (DSD), and turns it into a specifier of the wider category of Gender Dysphoria. While this change has attracted comparatively little critique and controversy so far, Kraus considers it as the "most significant change in the revised diagnosis" and draws out its consequences by comparing the classifications of intersex that different editions of the DSM have used. Noting that the recent change had been introduced in order to reduce risk of misdiagnosis as well as risk of stigmatization of intersex individuals, Kraus argues that DSM5 has, in fact, had the opposite effect. She shares Downing's view that the concept of "sex" operating in the DSM is based on a repronormative assumption as to what is "normal," and on a binary notion of gender which assumes that men and women can be clearly differentiated. The difficulty of placing intersex individuals neatly on this male-female binary thus automatically leads to classifying them as abnormal. Consequently, Kraus calls for the intersex/DSD label to be taken out of future editions of the DSM altogether.

Like Kraus, British sociologist and trans activist Zowie Davy turns her critical lens to the recent DSM shift from the category of Gender Identity Disorder to that of Gender Dysphoria, but where Kraus scrutinized its effects on individuals labelled as intersex, Davy explores its consequences for individuals who are classified as gender dysphoric. In her article "The DSM-5 and the Politics of Diagnosing Transpeople," she asks whether the DSM-5 has succeeded in the declared aim for this change: to lessen the potential stigmatization that might result from a trans diagnosis while at the same time protecting access to financial support for transitioning treatments from medical insurance companies, conditional upon medical diagnosis. She challenges the data that were used to justify this change in diagnostic labels, and argues that the new DSM-5 categories still risk stigmatization. Through her analyses of trans websites, forums, and blogs, Davy explores the personal experience narratives of transpeople, and shows that these represent a diverse anti-pathologization movement which mobilizes medical concepts and data in creative, contestatory ways. Davy documents the dissenting voices of those individuals who experience the effects of DSM classifications in their everyday lives, and the contestation of psychiatric classifications by grassroots movements. And yet this ongoing process of critical contestation takes place in a world where, as our opening article by Weeks suggested, it is impossible to live without labels.

To conclude, we would like to express our deep gratitude and warm thanks to the Editor for inviting us to put together this special section. Given that all of the articles collected in this special section express vigorous (though, we hope, constructive) criticism of the DSM or of psychiatric classifications more generally, Zucker's good-humored enthusiasm and unfailing support throughout the editorial process has been nothing short of remarkable. 